\title{
Survivors, Not Invaders, Control Forest Development Following Simulated Hurricane
}

\section{Citation}

Plotkin, Audrey Barker, David Foster, Joel Carlson, and Alison Magill. 2013. Survivors, Not Invaders, Control Forest Development Following Simulated Hurricane. Ecology 94, no. 2: 414423.

\section{Published Version}

doi:10.1890/12-0487.1

\section{Permanent link}

http://nrs.harvard.edu/urn-3:HUL.InstRepos:12332498

\section{Terms of Use}

This article was downloaded from Harvard University's DASH repository, and is made available under the terms and conditions applicable to Other Posted Material, as set forth at http:// nrs.harvard.edu/urn-3:HUL.InstRepos:dash.current.terms-of-use\#LAA

\section{Share Your Story}

The Harvard community has made this article openly available.

Please share how this access benefits you. Submit a story.

Accessibility 


\title{
Survivors, not invaders, control forest development following simulated hurricane
}

\author{
Audrey Barker Plotkin,,${ }^{1,4}$ David Foster,${ }^{1}$ Joel Carlson, ${ }^{2}$ and Alison Magill ${ }^{3,5}$ \\ ${ }^{1}$ Harvard Forest, Harvard University, 324 North Main Street, Petersham, Massachusetts 01366 USA \\ ${ }^{2}$ Northeast Forest and Fire Management LLC, 29 Moody Drive, Sandwich, Massachusetts 02563 USA \\ ${ }^{3}$ Earth Systems Research Center, University of New Hampshire, Durham, New Hampshire 03824 USA
}

Abstract. Wind disturbance profoundly shapes temperate forests but few studies have evaluated patterns and mechanisms of long-term forest dynamics following major windthrows. In 1990, we initiated a large hurricane simulation experiment in a 0.8-ha manipulation (pulldown) and 0.6-ha control area of a maturing Quercus rubra-Acer rubrum forest in New England. We toppled 276 trees in the pulldown, using a winch and cable, in the northwesterly direction of natural treefall from major hurricanes. Eighty percent of canopy trees and two-thirds of all trees $\geq 5 \mathrm{~cm}$ dbh (diameter at breast height) suffered direct and indirect damage. We used 20 years of measurements to evaluate the trajectory and mechanisms of forest response after intense disturbance. Based on the patch size and disturbance magnitude, we expected pioneer tree and understory species to drive succession.

The first decade of analyses emphasized tree seedling establishment and sprouting by damaged trees as the dominant mechanisms of forest recovery in this extensive damaged area. However, despite $80 \%$ canopy damage and $8000-\mathrm{m}^{2}$ patch size, surviving overstory and advance regeneration controlled longer-term forest development. Residual oaks make up $42 \%$ of stand basal area after 20 years. The new cohort of trees, dominated by black birch advance regeneration, contributes $30 \%$ of stand basal area. There were shifts in understory vegetation composition and cover, but few species were gained or lost after 20 years. Stand productivity rebounded quickly (litterfall recovered to pre-disturbance levels in six years), but we predict that basal area in the pulldown will lag behind the control (which gained $6 \mathrm{~m}^{2}$ /ha over 20 years) for decades to come. This controlled experiment showed that although the scale and intensity of damage were great, abundant advance regeneration, understory vegetation, and damaged trees remained, allowing the forest to resist changes in ecosystem processes and invasion by new species.

Key words: 1938 hurricane; Acer rubrum; Betula lenta; disturbance; Harvard Forest, Massachusetts, USA; hurricane; LTER; New England, USA; Quercus rubra.

\section{INTRODUCTION}

Wind disturbance strongly shapes forest structure, function, and dynamics in temperate forests (Boose et al. 2001, Papaik and Canham 2006). Major hurricanes generate large but heterogeneous openings, increased coarse woody debris, pit-and-mound microtopography, and major changes in understory light and temperature availability. Overstory trees exhibit a range of responses to wind events, including sudden or delayed mortality, reduced or enhanced growth, recovery, and sprouting (Cooper-Ellis et al. 1999). These impacts leave enduring legacies in the structure and composition of the overstory and understory.

The trajectories of vegetation change following windstorms and the mechanisms underlying these

Manuscript received 26 March 2012; revised 19 September 2012; accepted 26 September 2012. Corresponding Editor: M. C. Wimberly.

${ }^{4}$ E-mail: aabarker@fas.harvard.edu

5 Present address: 37 Fogarty Road, Barrington, New Hampshire 03825-5512 USA. changes are poorly understood (Lugo 2008) despite many post hoc studies of forest response to wind. For example, in New England, hypotheses of the role of windstorms in structuring forest dynamics are strongly influenced by studies of the 1938 "Great Hurricane." Like many studies of disturbance, research on the 1938 hurricane lacked both controls and systematic beforeand-after measurements (Rowlands 1941, Foster $1988 a, b$, Merrens and Peart 1992) and emphasized immediate impacts and intermittent multi-decadal sampling rather than continuous trajectories (cf., Spurr 1956, Henry and Swan 1974, Mabry and Korsgren 1998). Such studies may miss critical stages in recovery, such as regeneration and the mechanisms involved, or short-lived episodes of rapid growth or population expansion. Finally, although interpreted in terms of natural processes, the 1938 event was strongly conditioned by cultural history and activity (Foster et al. 1997). New England was a post-agricultural landscape dominated by successional Pinus strobus in abandoned fields that were more susceptible to wind damage than native mixed hardwood and conifer forests (Foster 

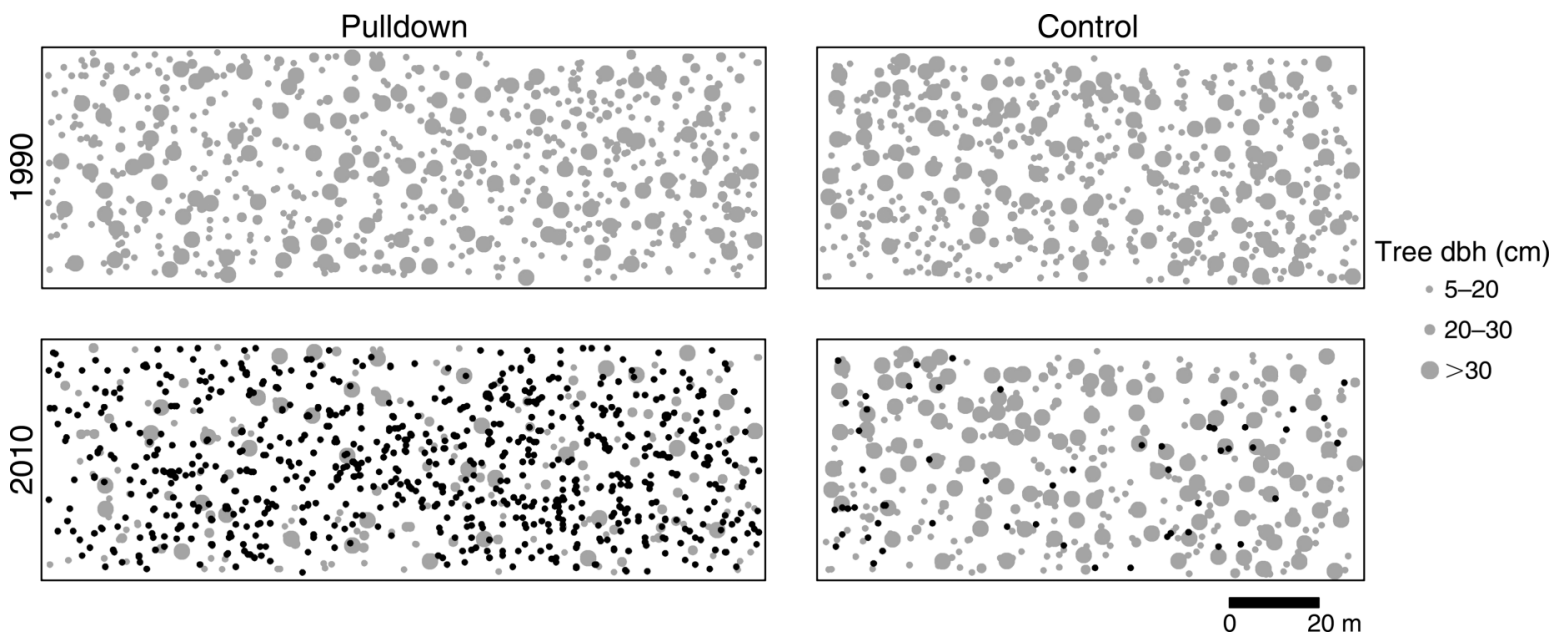

FIG. 1. Stem maps of the pulldown and control sites before the manipulation (1990) and after 20 years (2010) of a large hurricane simulation experiment in a Quercus rubra-Acer rubrum forest in New England, USA. The long axes of the plots are oriented approximately east-west. In the upper panels, gray points represent all trees living in 1990. In the lower panels, gray points show trees that survived from 1990 to 2010, and black points represent live trees in 2010 that had been recruited into the tree-sized ( $>5 \mathrm{~cm}$ diameter at breast height $[\mathrm{dbh}])$ class since 1990.

1988b). The culturally conditioned patterns of forest damage were modified by region-wide salvage harvesting of downed and damaged trees, soil scarification, and the burning of slash (NETSA 1943); in many aspects the salvage was a more profound disturbance than the hurricane itself (Foster and Orwig 2006). Consequently, the understanding of post-hurricane forest dynamics emerging from the 1938 event is suspect as a representation of natural forest dynamics.

In 1990, an "experimental hurricane" was established in a mixed hardwood forest in order to examine the patterns and mechanisms of damage and recovery following canopy blowdown more rigorously. Gap theory emphasizes spatial scale of disturbance as a key determinant of regeneration and future forest composition (Whitmore 1989, Sipe and Bazzaz 1994). Thus, the $8000-\mathrm{m}^{2}$ hurricane simulation was expected to follow the catastrophic regeneration mode described by Veblen (1992), in which the pulse regeneration of shade-intolerant woody and herbaceous species following large-scale disturbance allows them to coexist with more tolerant species.

This framework led to an initial hypothesis that newly established seedlings of light-demanding pioneer species would play a major role in the new forest canopy. Consequently early efforts (Carlton and Bazzaz 1998) investigated seedling regeneration in the complex microenvironments of the hurricane manipulation, focusing especially on congeneric Betula species ( $B$. lenta, $B$. alleghaniensis, and $B$. papyrifera). Their finding that the pioneer B. papyrifera grew the fastest fit well with gap theory and led them to predict that it would be the most likely species to recruit into the canopy. Cooper-Ellis et al. (1999) reported vigorous seedling establishment and colonization of light-demanding understory vegetation in the first six years following the disturbance, but also noted a surprising amount of survival and sprouting response of damaged trees. At this point in the study's trajectory, the hypothesis that sprouts could dominate forest regeneration emerged, as was observed in tropical forests by Putz and Brokaw (1989).

After 20 years, we can assess how well the long-term trajectories of forest regeneration and forest tree and understory composition match these earlier observations and predictions. The presence of a surprisingly dynamic control plot also allows an assessment of the divergence of developmental trajectories in the damaged and undisturbed forests. Based on the patch size and disturbance magnitude, we expected regeneration at the manipulated site to fit the catastrophic regeneration mode (Veblen 1992), with pioneer tree and understory species driving succession.

\section{Methods}

\section{Experimental design and manipulation}

The hurricane manipulation experiment is located on a gentle northwest slope in the Tom Swamp Tract of the Harvard Forest $\left(72.20^{\circ} \mathrm{N}, 42.49^{\circ} \mathrm{W}, 300-315 \mathrm{~m}\right.$ a.s.1., above sea level) on well-drained to moderately welldrained stony loams derived from glacial till overlying schist bedrock. The 75-year old Quercus rubra-Acer rubrum forest developed following a clearcut in 1915 (Harvard Forest Archives, unpublished data). The study area is surrounded by similar forest. The climate is cool temperate (July mean $20^{\circ} \mathrm{C}$, January mean $-7^{\circ} \mathrm{C}$ ); 1100 $\mathrm{mm}$ average precipitation is distributed evenly throughout the year.

A 0.8 -ha experimental site $(50 \times 160 \mathrm{~m}$, the "pulldown") and 0.6 ha $(50 \times 120 \mathrm{~m})$ control site were oriented approximately east to west and separated by a 30-m forest buffer (Fig. 1). Given limited resources, we 
established a single large plot representative of hurricane damage patch size in this landscape (Foster and Boose 1992), and analyzed our data with before-after-treatment analysis. Prior work (Rowlands 1941, Foster $1988 b$ ) that examined the relationship between damage and forest composition and age in the 1938 hurricane guided the level of damage in this experiment, which was controlled by pulling down selected trees. During peak hurricane season in early October 1990, 276 trees were toppled in a northwesterly direction of natural treefall (Boose et al. 2001), using a winch and steel cable attached $\sim 6 \mathrm{~m}$ up the bole of each tree. Force was applied by the winch only until the stem or roots failed and the mass of the crown brought the tree down. Stems were not pulled beyond their initial point of repose. The winch was positioned off the study site so that all plant and soil disturbance resulted from uprooting or bole breakage, plus damage to 325 trees hit by the toppled trees. The manipulation effectively simulated the effects of a hurricane in terms of overstory damage, damage to intermediate and understory vegetation, and physical structure. Eighty percent of the canopy trees, and twothirds of all trees $\geq 5 \mathrm{~cm}$ dbh, were damaged directly or indirectly by the manipulation. The manipulation also strongly altered microsite conditions: following the pulldown, pits and mounds covered $8 \%$ of the site and uprooted tree stems and branches covered 13\% (CooperEllis et al. 1999).

\section{Field sampling}

Prior to the manipulation, all trees $\geq 5 \mathrm{~cm}$ dbh were tagged and a $10-\mathrm{m}$ grid and tree coordinates were mapped using tree-to-tree distance measurements and the INTERPT program (see Boose et al. 1998, Harvard Forest Data Archive: HF023 for detailed methods). Immediately following the manipulation, all damaged trees were classified as bent, leaning, snapped, or uprooted. Before the manipulation (1990), annually from 1991 to 1996, and in 2000, 2005, and 2010, we followed survival and sprouting of each individual tree in the pulldown and control sites. Crown vigor was rated on a four-point scale, presence/absence of trunk sprouts noted, and basal sprouts counted. Tree diameters were measured in 1990, 1996, 2000, 2005, and 2010. Recruitment of trees to the $>5 \mathrm{~cm}$ dbh size class was tallied (diameter, species, growth form, microsite, location) across both sites in 2000, 2003, 2006, and 2009. In 2010, live recruits were tagged and mapped to the nearest $0.5 \mathrm{~m}$ based on their locations relative to grid posts and surviving trees. Diameter distributions were constructed with 5-cm size class intervals using the 1990 and 2010 diameter measurements for all trees (including recruits in 2010). In addition, a post-disturbance diameter distribution was constructed for the pulldown by excluding trees that ceased leafing by 1996 (i.e., a tree that leafed out in the first $1-5$ years but subsequently died is excluded from this set).
Regeneration and understory dynamics were assessed in $242 \times 5 \mathrm{~m}$ plots randomly established on each of three east-west transects in the pulldown $(n=72)$ and on one transect in the center of the control $(n=24)$. The three transects in the pulldown were placed in the north, center, and south of the plot to capture within-plot gradients. Individual sapling (stems $>30 \mathrm{~cm}$ tall and $<5$ $\mathrm{cm}$ diameter) growth and survival were measured every three years (1990-1999) in these plots and classified as advance regeneration (established in advance of the manipulation), sprout, or of new seedling origin. Before (1990) and after (1991, 1992, 1995, 2000, 2005, and 2010) the manipulation, the composition, and abundance (cover to the nearest 1\%) of shrubs were recorded in these plots, and herb composition and percent cover were sampled in $1-\mathrm{m}^{2}$ subplots nested within the sapling/ shrub plots.

Litterfall was collected from 13 plastic laundry baskets in the experimental site and 12 baskets in the control site (basket area $0.2345 \mathrm{~m}^{2}$ each) three times each year. Oven-dry mass was determined, and annual litterfall mass was estimated by combining the main leaf fall collected in November with the subsequent June and early September collections (e.g., 2009 annual litterfall is the sum of November 2009, June 2010, and September 2010).

Dead wood volumes were estimated using data from a fuel-loading survey. We followed planar intersect methods of Brown (1974), except that rooted (but dead) pieces were included (e.g., partially uprooted trees and their branches). In 1993, 12 planar transects $16 \mathrm{~m}$ long were sampled in the pulldown, and 16 transects in the control. This survey was repeated in 1998 and 2010. Volume of coarse woody debris was calculated from pieces $\geq 7.5 \mathrm{~cm}$ diameter.

\section{Statistical analyses}

Twenty years is not long enough in the life of a forest to develop meaningful time series analyses; rather, we analyzed trajectories of change using ANCOVA, with treatment as a fixed factor and time as a continuous covariate (A. M. Ellison and N. J. Gotelli, unpublished manuscript). Contrasts between the pulldown and control reveal any differences in magnitude of response. The interaction term (time $\times$ treatment) indicates whether the pulldown differs from the control in direction or rate of response. Prior to analyzing trajectories of change for litterfall, basal area, and understory vegetation cover, data were scaled to the 1990 pretreatment observations by dividing each observation in a treatment by the pretreatment value. We used site-level averages of observations from multiple plots per site (shrub and herb cover, litterfall) to avoid spatial pseudoreplication. Analyses were conducted in $\mathrm{R}$ 2.9.2 (R Development Core Team 2009).

In the pulldown, litterfall increased rapidly for the first few years, then appeared to stabilize. A breakpoint (identified with the R strucchange library; Zeileis et al. 
[2002]) in the relationship between time and litterfall was detected at year 6 in the pulldown data (Appendix C: Table C2), so we analyzed the two subsets of data (19911996 and 1997-2010) separately.

We evaluated changes in the community composition of shrubs and herbs using mean abundance of each species for each year and treatment. Species not found in a minimum of three of the 14 year/treatment combinations were excluded from the ordinations; Carex, Rubus, Vaccinium, and Viola species were pooled into their respective genera. Nonmetric multidimensional scaling (NMDS) ordination was performed using the function metaMDS in the vegan package (Oksanen et al. 2012). Bray-Curtis dissimilarities and $k=3$ were used for both shrubs and herbs. Increasing $k$ resulted in lower stress but very similar results, so the simpler models were chosen. Double Wisconsin standardization was applied to the herb data based on the default thresholds in the metaMDS command.

\section{REsults}

Changes in the structure and composition of the arboreal layers

The pulldown and control sites had similar initial basal area and density (Appendix A). The experimental manipulation killed about half of the trees within three years, and by 2010 , only $31 \%$ of the original trees $>5 \mathrm{~cm}$ dbh remained living. After 10 years, recruitment had replenished tree numbers, but basal area in the pulldown plot was still $78 \%$ of the pre-manipulation amount in year 20 (Fig. 2a; effect of year $F_{1,6}=67.88, P<0.001$; treatment $F_{1,6}=462.58, P<0.001$; year $\times$ treatment $F_{1,6}$ $=6.69, P=0.041 ;$ a full summary table for the ANCOVA analyses is in Appendix C: Table C1). Leaf area in the pulldown site recovered in six years (breakpoint 95\% CI encompassed years 3-8; Fig. 2b). Litterfall in the pulldown increased from 1991 to 1996 (year $F_{1,8}=$ $8.35, P=0.020)$, but was steady $(P=0.57)$ and did not differ from the control $(P=0.34)$ from 1997 to 2010. Litterfall remained steady in the control over the 20 years $(P=0.914)$.

Forest structure and composition were shaped in the pulldown by a combination of survivors and a new cohort of trees (Fig. 3). Although surviving Q. rubra contributed $42 \%$ of the 2010 basal area (a decrease from $67 \%$ in 1990), it comprised $<1 \%$ of the new cohort. $A$. rubrum numbers decreased but it contributed relatively more basal area in $2010(19 \%)$ than in $1990(13 \%)$ with a combination of undamaged survivors, recovering damaged trees and regeneration from sprouts and saplings. Betula lenta basal area increased from 3\% to $21 \%$ from 1990 to 2010, mainly as recruits from advance regeneration. Light-demanding species including Prunus seroti$n a$ and P. pensylvanica, B. papyrifera, and Pinus strobus collectively contributed $\sim 8 \%$ of the 2010 basal area. The control plot, in contrast, has a bimodal diameter distribution mainly composed of large diameter $Q$. rubra and small diameter A. rubrum, and negligible
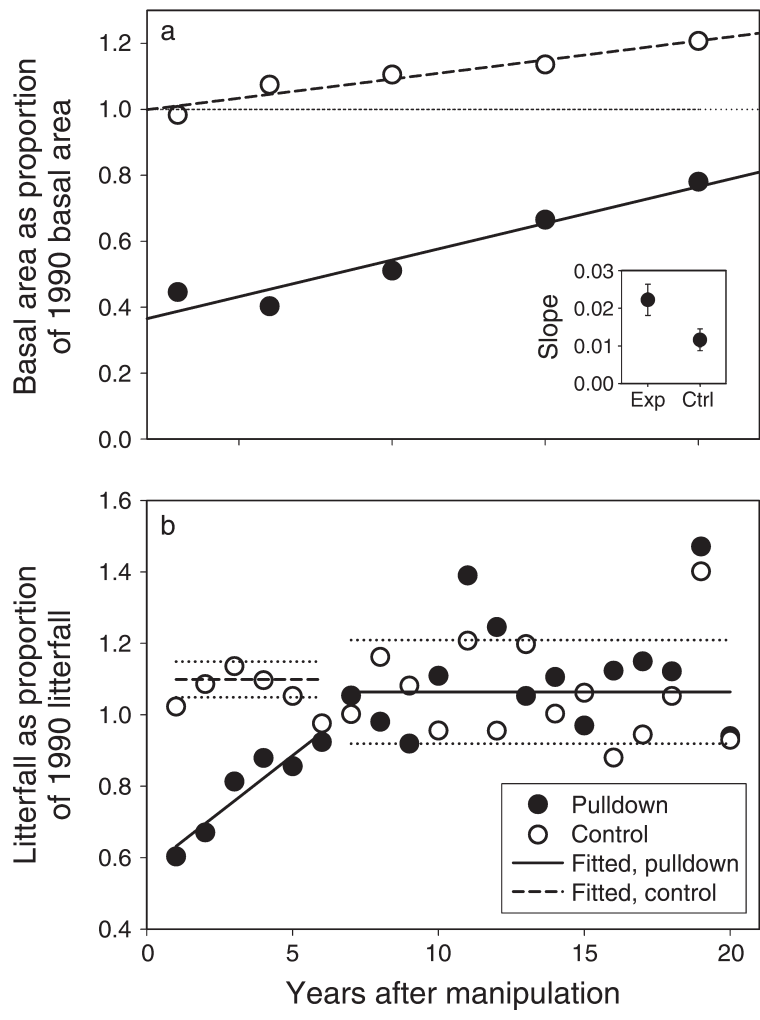

FIG. 2. Trajectories of change in (a) basal area and (b) litterfall. Basal area and litterfall data were scaled to the 1990 pretreatment observations by dividing each observation in a treatment by the pretreatment value, to show how the pulldown and control changed over time compared to their respective pretreatment baseline values. (a) Although basal area in the pulldown was gained at about twice the rate as in the control (inset shows slope $\pm \mathrm{SE}$ ), the steadily accruing basal area in the control will slow the pulldown site from reaching control levels for decades. (b) Litterfall increased rapidly in the pulldown from 1991 to 1996, followed by steady litterfall that did not differ from the control from 1997 to 2010 . Litterfall was steady across 20 years in the control; although fitted litterfall differed slightly between the first and second periods, the two estimates fall within the standard error of one another (dotted lines).

contribution of new recruits in 2010. Q. rubra increasingly dominates the control site (rising from $70 \%$ to $80 \%$ basal area from 1990 to 2010).

Canopy tree species richness changed little over 20 years. The pulldown site gained three tree species (Populus grandidentata, Prunus pensylvanica, and Tsuga canadensis), and so rose from 14 tree species to 17 species. The control site gained one tree species (Fagus grandifolia grew into the tree-size class) and lost one (the one stem of Tilia americana), to remain at 13 tree species.

Coarse woody debris volume in the pulldown site was an order of magnitude larger than in the control (Fig. 4). Volume increased slightly from 1993 to 1998, likely due to the delayed death of uprooted trees. Much of the downed wood initially was suspended at least $0.5 \mathrm{~m}$ from the ground. By 2010, volume had decreased from 

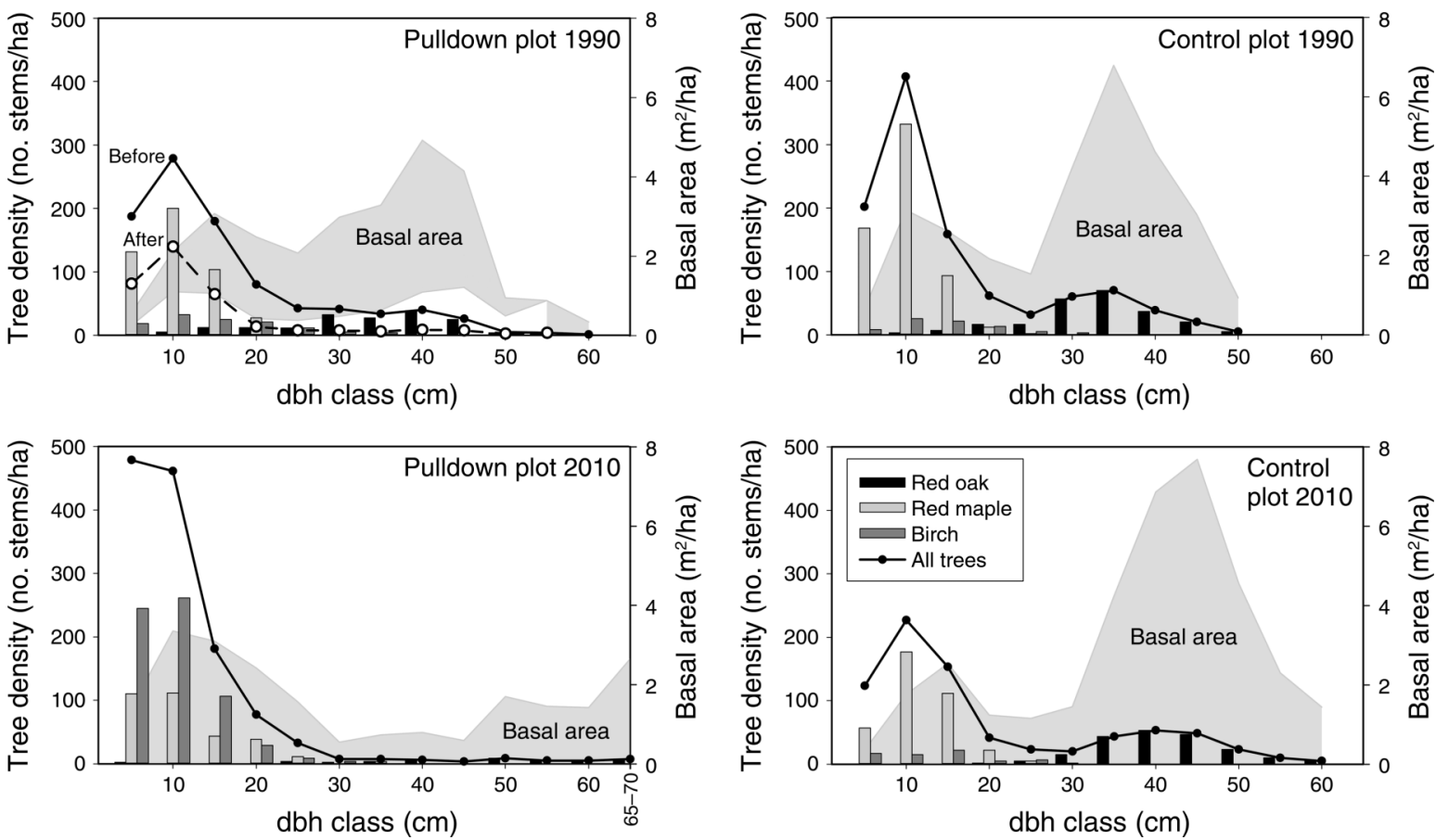

FIG. 3. Distributions of dbh at the beginning of the study (1990) and after 20 years (2010) for all stems (lines) and major species (bars). Basal area distribution by size class is shown as the gray area backdrop. In addition, the trees that survived the manipulation are shown by the dotted line and open circles (number of stems) and white area backdrop (basal area), shown in pulldown plot 1990 only. Although there were few Q. rubra in the pulldown in 2010 (46 trees/ha from 15 to $70 \mathrm{~cm}$ diameter, most $>35 \mathrm{~cm}$ diameter), these contributed $42 \%$ of the 2010 basal area. Major species were: red oak, Quercus rubra; red maple, Acer rubrum; birch, Betula species.

$240 \mathrm{~m}^{3} /$ ha to $182 \mathrm{~m}^{3} / \mathrm{ha}$, and had settled to the forest floor. Average piece diameter was $16-19 \mathrm{~cm}$ in the pulldown, and $10-11 \mathrm{~cm}$ in the control.

\section{Mechanisms of regeneration}

Trees regenerated through three mechanisms: advance regeneration, sprouting of damaged trees, and new seedlings. Prior to the manipulation, there were 5700 stems/ha of advance regeneration in the pulldown. $P$. serotina and $B$. lenta/alleghaniensis were most numerous, but $A$. rubrum stems were relatively larger. In 1990 there were 3250 stems/ha of advance regeneration in the control. A. rubrum was the most important, followed by P. serotina, B. lenta/alleghaniensis, and Pinus strobus. Sapling numbers in the pulldown increased fourfold by 1993, then declined (Fig. 5a). In the control they increased 70\% from 1990 to 1999.

Advance regeneration density increased modestly in the pulldown and control sites from 1990 to 1996, as stems that originated prior to 1990 grew above the $0.3 \mathrm{~m}$ height threshold. Seedlings that established after the manipulation comprised the majority of the regeneration pool in the pulldown, and about one-quarter of the saplings in the control by 1999. Sprouting from damaged trees was rapid and prolific after the manipulation (Fig. 6; year $F_{1,10}=3.27, P=0.101$ and year $^{2}$ $\left.F_{1,10}=23.24, P<0.001\right)$. Sprouting increased in the
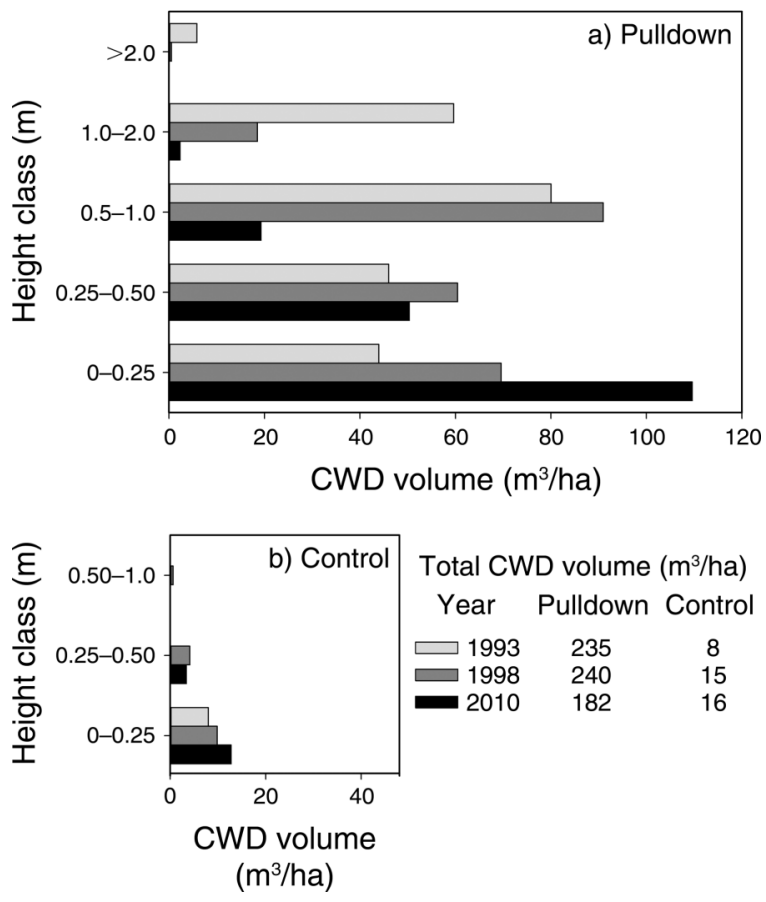

FIG. 4. Volume of coarse woody debris (CWD) over time and by height from the ground in the (a) pulldown and (b) control sites. 

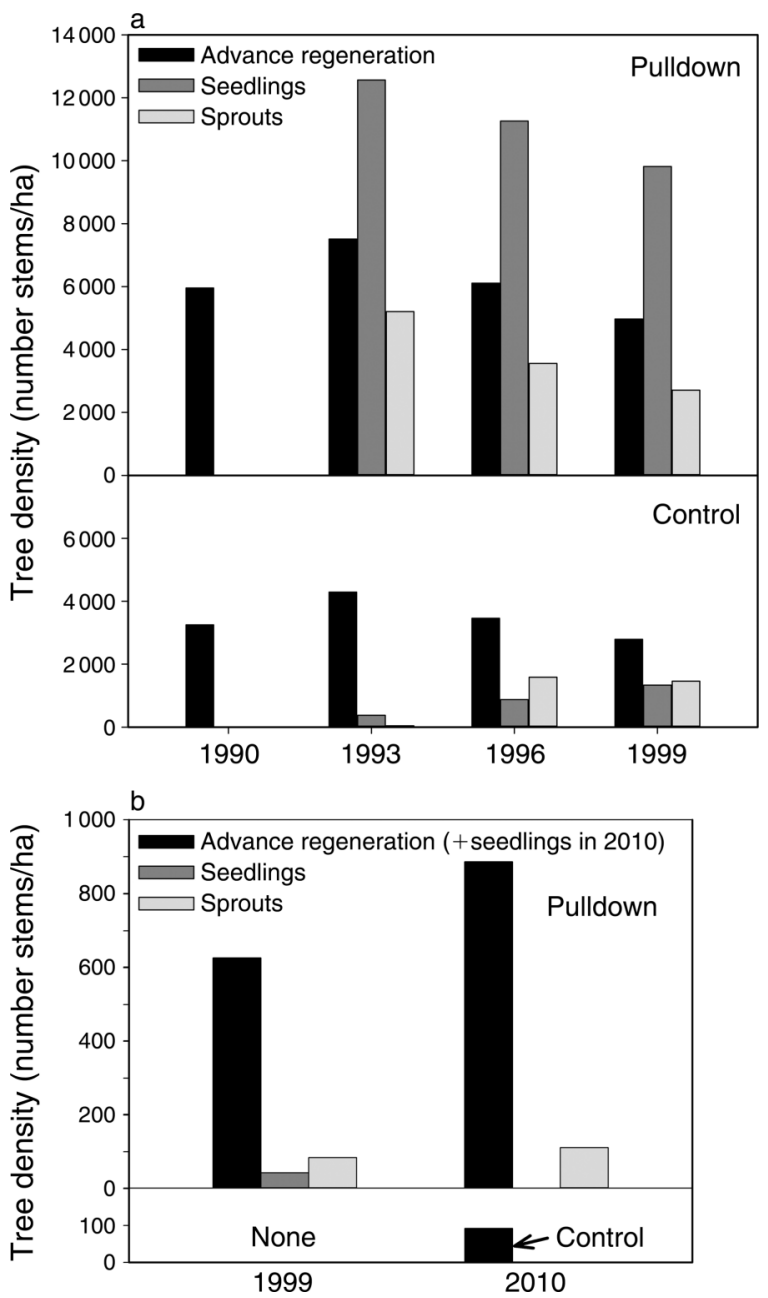

FIG. 5. Tree regeneration density by advance regeneration (established in advance of the manipulation), seedlings, and sprouts for (a) stems $>0.3 \mathrm{~m}$ tall (1990-1999) and (b) the subset of these stems that crossed the tree-sized $(5 \mathrm{~cm} \mathrm{dbh})$ threshold in 1999, based on tracking individuals in subplots. Data for 2010 are from a census of all live new stems; it was not possible to distinguish advance regeneration from seedling origin stems so the small number of seedling-origin trees is lumped into the "advance regeneration" bar. Betula lenta, B. alleghaniensis, and Acer rubrum were the most common species throughout the 20 years; by $2010,48 \%$ of the new tree-sized stems were $B$. lenta, and $18 \%$ were $A$. rubrum.

control site as well, but more slowly (treatment $F_{1,10}=$ 17.40, $P=0.002$ and year $\times$ treatment $F_{1,10}=12.40, P=$ 0.006 ); the number of trees with basal sprouts in the two sites was similar for years 10-20. In 1993, sprouts comprised $\sim 20 \%$ of the pulldown regeneration pool, but attrition caused their importance to decline to $15 \%$ in 1996 and 1999 (Fig. 5a).

Relative importance of the regeneration mechanisms shifted when we examined which saplings grew into the tree-sized ( $\geq 5 \mathrm{~cm} \mathrm{dbh}$ ) cohort. Although new seedlings dominated the regeneration pool, advance regeneration contributed $>80 \%$ of recruits in 1999 (Fig. 5b) in the pulldown, whereas new seedlings and sprouts contributed $6 \%$ and $11 \%$, respectively. In 2010 , the new cohort was dominated by $B$. lenta advance regeneration. In 1999 , there were no recruits in the control, but some ( $\sim 10 \%$ as many as in the pulldown) by 2010 .

\section{Response of the understory flora}

More than twice as many herb and shrub species were added or lost to the pulldown plots than the control plots (Appendix B), but most of these changes were transient. At the end of 20 years, a total of four species were lost and six added in the pulldown, whereas the control site lost three and gained four species.

The pulldown herbaceous community (forbs, ferns, graminoids) composition reached its maximum dissimilarity with pre-disturbance conditions in 1995 on NMDS axis 1 and in 2005 on NMDS axis 2 (Fig. 7a). Some of the species that plotted near the pulldown herbaceous community in 1995 were transient colonizers of disturbed areas, such as Erechtites hieracifolia, Lobelia inflata, Potentilla simplex, and Solidago species. The control herb community showed modest change along NMDS axis 2 over the 20 years. Herb cover in the pulldown showed no significant changes over time or in contrast to the control (Fig. 8a).

The pulldown shrub community reached its maximum dissimilarity with pre-disturbance composition and cover 5-10 years after the manipulation (Fig. 7b). Some of the shrub species associated with these years colonized the site following the manipulation (e.g., Rubus species, Sambucus pubens, and Rhus typhina). Two invasive shrubs entered the site following manipulation (Lonicera morowii and Celastrus orbiculatus); by 2005, L. morowii had died but C. orbiculatus persisted. By 2010, the pulldown shrub community returned to nearly the same ordination plot location as its starting point. The control shrub community showed modest directional change over the 20 years. In the control plot overall shrub cover more

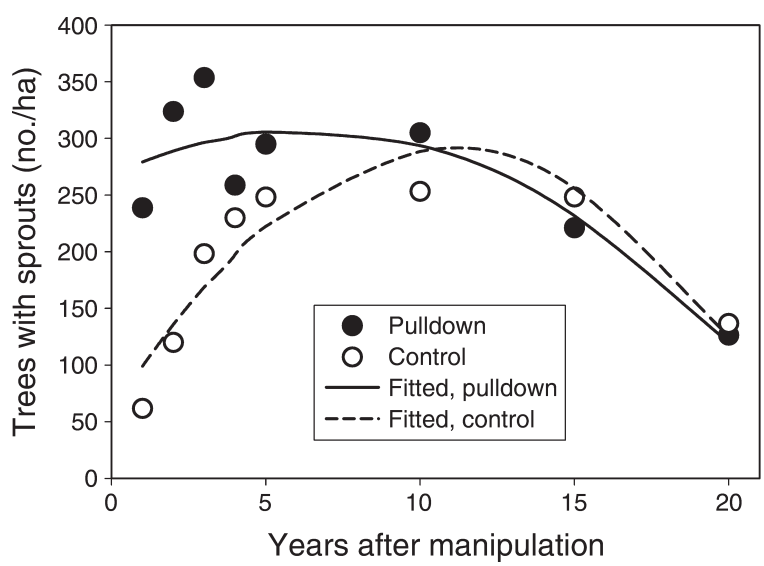

FIG. 6. Trajectories of change in the number of trees with basal sprouts in the pulldown and control sites. Fitted lines are significant polynomial ANCOVAs using centered values for "year." 

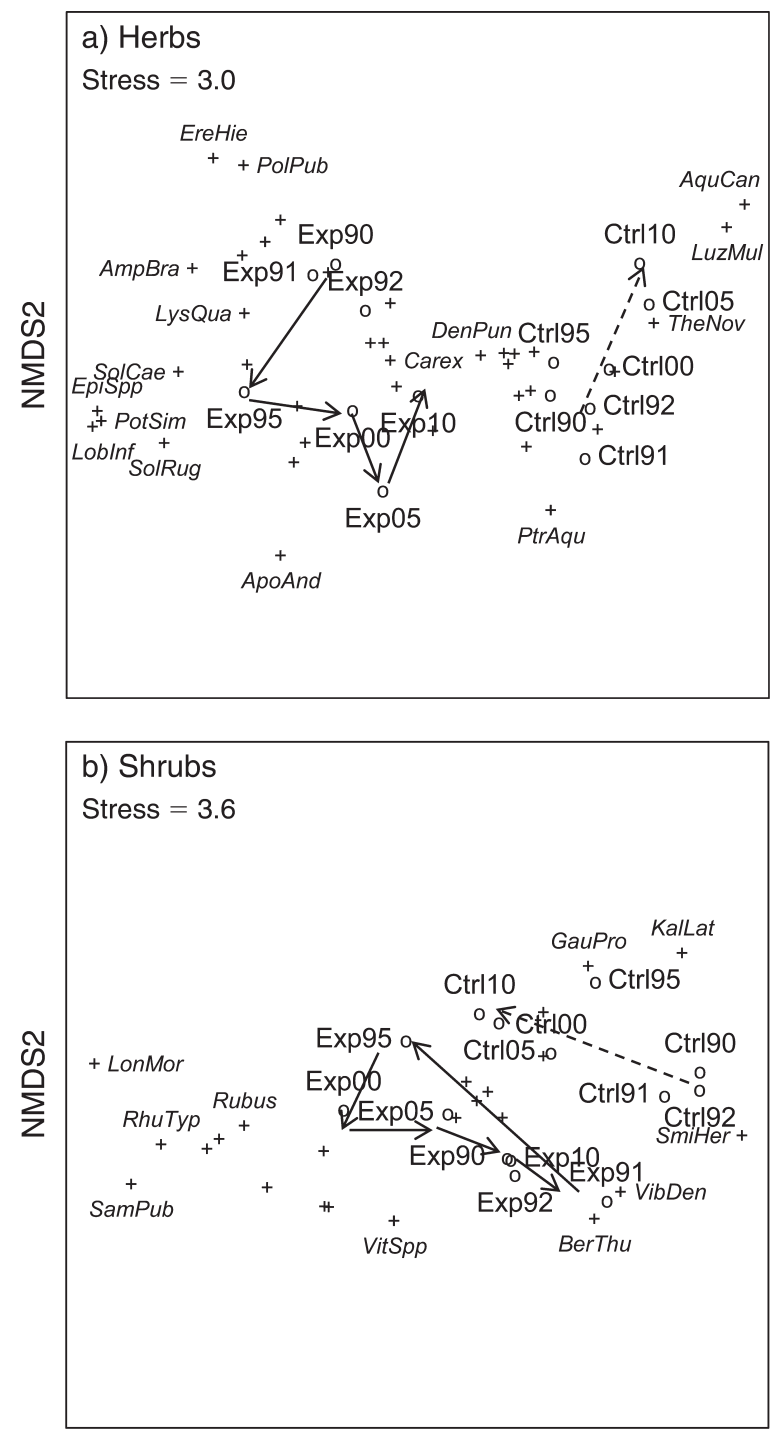

NMDS1

FIG. 7. NMDS (nonmetric multidimensional scaling) ordinations showing changes in the (a) herb and (b) shrub communities. Arrows (solid, experimental sites; dashed, control sites) follow trajectories of community change over time. Sites (open circles) are labeled by treatment and year (e.g., Exp10 is the experimental site in 2010; Ctr190 is the control plot in 1990). Species $(+)$ labeled illustrate species that changed the most, or that differed between the pulldown and control. These are labeled by the first three letters of the genus and the first three letters of the species (Appendix B provides a species list.)

than tripled from $2.2 \%$ to $7.7 \%$ average cover from 1990 to 2010 , whereas in the pulldown shrub cover increased for the first 10 years, then declined from year 10-20 (Fig. $8 b)$. We observed shrub dieback in several pulldown plots during the 2005 survey.

\section{DisCUSSION}

Our 20-year, controlled hurricane experiment allows better understanding of the trajectories and mechanisms of forest responses to, and recovery from, intense windstorms. The experiment effectively mimicked patch size and natural damage observed in hardwood stands following the 1938 hurricane (Foster 1988b, Foster and Boose 1992). Surprisingly, many of the damaged and even prostrate trees survived, produced leaves, and sprouted vigorously for 2-3 years following the experimental treatment (Cooper-Ellis et al. 1999). The maintenance and development of substantial leaf area from surviving and sprouting damaged trees muted microenvironmental changes and helped to stabilize ecosystem processes; few changes were observed in soil temperature, moisture, respiration and carbon fluxes, or nitrogen dynamics in the year after the manipulation (Bowden et al. 1993). Now, 20 years into the study, the forest has passed through the first stages of vegetation reorganization.

\section{Survivors control the regeneration process}

In contrast to our early expectations that seedlings germinating in response to the manipulation would dominate tree regeneration, we found that survivors, not invaders, control the composition and structure of the disturbed forest. Although $80 \%$ of the existing canopy was damaged, the few surviving $Q$. rubra continue to
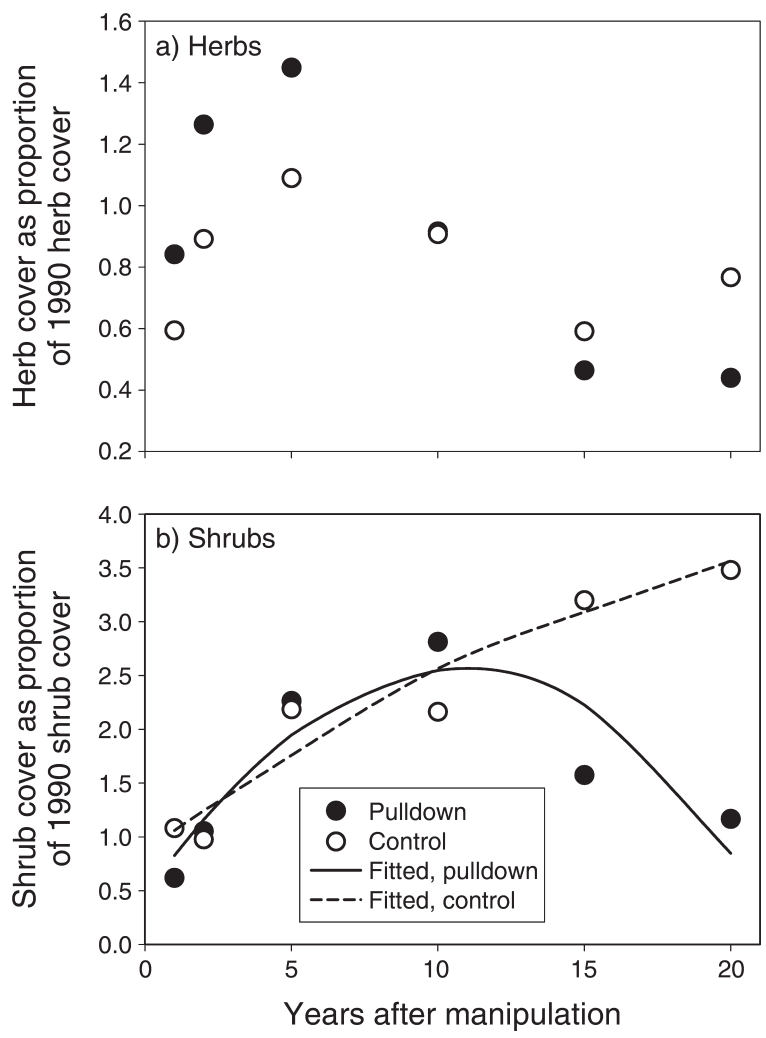

FIG. 8. Trajectories of change in (a) herb cover and (b) shrub cover. ANCOVA analysis showed no significant changes in herb cover between treatments or over time; the fitted lines for shrubs are significant polynomial ANCOVAs using centered values for "year." 
dominate stand basal area. The new cohort was mainly composed of advance regeneration that was established in the understory before the disturbance. Sprouts from damaged trees initially stabilized the site, modulated the understory environment, and made a minor contribution to the new cohort, and a few fast-growing seedlings, often on mound microsites, played a minor role in the new cohort. Light-demanding seedlings of $B$. papyrifera and $P$. serotina comprised $15 \%$ and $14 \%$ of the saplings $>0.3 \mathrm{~m}$ tall in the pulldown in 1993 (Cooper-Ellis et al. 1999), but few of these recruited into the new canopy as competition from advance regeneration and shading from surviving and sprouting damaged trees reduced their access to light and other resources (cf., Peterson and Pickett 2000). Similarly, disturbance-associated shrubs and herbs colonized the pulldown plot, but few persisted beyond the first decade. Rather than gap theory (Whitmore 1989, Veblen 1992), these findings better fit multidimensional disturbance models such as that proposed by Roberts (2004), which explicitly include understory and forest floor disturbance intensity in addition to canopy damage. Although $80 \%$ of the canopy was removed, the understory and forest floor ( $8 \%$ of the area was covered by pits and mounds; Cooper-Ellis et al. 1999) remained mostly intact.

Establishing the experiment in a mixed-hardwood forest allowed us to investigate the role of vegetative reproduction in forest recovery. The sprouting response of damaged trees, especially by the abundant $A$. rubrum (Cooper-Ellis et al. 1999), was critical in stabilizing the site and created a strong environmental filter for vegetation reorganization. Given the large established root system of sprouts, we expected that they would make a major contribution to the new tree canopy, as observed by Putz and Brokaw (1989) and Dietze and Clark (2008). However, the sprouts declined after the first decade and ultimately contributed few stems to the new canopy (Fig. 6). The brief increase in sprouting in the control is likely associated with minor canopy disturbance from a heavy winter snow in 1992 (J. O'Keefe, unpublished data).

\section{Burgeoning Betula lenta}

Twenty years after the manipulation, B. lenta advance regeneration accounted for nearly half of the new cohort of trees. Fajvan et al. (2006) found that B. lenta advance regeneration had the strongest height growth in the pulldown, compared to other species or conspecific new seedlings of similar height. The dominance of $B$. lenta in forming the new forest canopy was unexpected. It is a common, but rarely dominant, overstory species. Although it is recognized as a mound specialist in hurricane gaps (Henry and Swan 1974), B. lenta was able to grow into the canopy from both established seedlings and new seedlings on all microenvironments. Its importance may decline as the forest further develops; however, Motzkin et al. (1999) found that 1938 hurricane damage had a strong positive influence on overstory $B$. lenta importance more than 50 years after the storm.

In recent decades, $B$. lenta has responded strongly to other disturbances in the region (Ward and Stephens 1996), including the decline of Tsuga canadensis by the invasive hemlock woolly adelgid (Adelges tsugae; Orwig and Foster 1998). In T. canadensis forests, nearly all regeneration is from seed, as the deep shade cast by the canopy precludes advance regeneration. Although not well documented, the ability of $B$. lenta to act both as a pioneer (establishing from seed in large openings) or a more shade-tolerant juvenile (establishing under a closed canopy) fits its intermediate shade tolerance and provides a flexible response to a variety of disturbances. It is possible that this species is becoming more prominent as a result of enhanced deposition of nitrogen from fossil fuel combustion (cf., Aber and Magill 2004). $B$. lenta responds strongly to increased availability of nitrate (Crabtree and Bazzaz 1993), which often occurs after canopy disturbance (Orwig et al. 2008). Although small, an increase in nitrate was observed during the first season after the pulldown (Bowden et al. 1993).

B. lenta shares a generalist strategy with A. rubrum, which is second in importance in the new cohort and exhibits characteristic flexibility (Abrams 1998) by contributing stems from advance regeneration and sprouts from damaged overstory stems. Although residual $Q$. rubra dominates the pulldown basal area, it was nearly absent from the new cohort.

\section{Converging, diverging, and persisting trajectories of change}

The analyses in this paper are designed to contrast the trajectories of response between the pulldown and control sites. In some cases (basal area, shrub cover), this framework magnified the differing trajectories between the control and pulldown. In others, the fluctuations observed in the pulldown (herb cover, sprouting after the first decade) are mirrored in the control. Such contrasts are more powerful than those from post hoc comparisons in natural experiments.

Trajectories in the pulldown site that rapidly converged with the control include litterfall mass (which can be used as a proxy for stand leaf area; Marshall and Waring [1986]), sprouting, and understory vegetation composition. Litterfall mass remained constant in the control site throughout the study. The pulldown site matched that level only six years after the manipulation and thereafter the two sites were the same. Understory flora can provide more persistent indicators of disturbance than the trees (Motzkin et al. 1999), but in this case only six of the 22 new herb and shrub species (plus numerous Carex species) that colonized the pulldown plots persisted to year 20 (Appendix B), and some of those (e.g., three Rubus species) became much less abundant over time. Most understory species present prior to the manipulation persisted over the study period in both the pulldown and control sites. 
The pulse of dead wood added to the forest is far larger than dead wood volumes found typically in forests of this region, including old-growth stands (D'Amato et al. 2008), and contrasts sharply with most of the landscape that has experienced land clearing for agriculture, and salvage harvest of trees after the 1938 hurricane. The large, slowly decomposing pool of coarse woody debris will persistently affect nutrient cycling, carbon dynamics, and habitat structure for many decades. In contrast, dead wood volumes remained low in the control site throughout the study period.

Trajectories that show slow convergence or divergence were driven by changes in both the pulldown and control sites. For example, shrub cover (Fig. 8b) increased in both sites for years $1-10$, but in years 1120 shrub cover decreased in the pulldown as it entered the stem exclusion phase of stand development, while the control continued to gain shrub cover as it entered the understory reinitiation phase of development (Oliver and Larson 1996).

Notably, the control site added $20 \%$ biomass (as estimated by basal area) as it developed from age 75 to 95 , markedly slowing convergence between the control and pulldown (Fig. 2a). Although the pulldown site is gaining basal area more rapidly than the control and should recover to its pre-disturbance basal area by about year 30, it will lag behind the growing control for decades to come, with implications for carbon storage (Zeng et al. 2009). In addition, although there was little turnover in tree species composition, the relative abundances of major species diverged over time, with increasing importance of $Q$. rubra in the control and emergence of a novel B. lenta-dominated cohort in the pulldown.

\section{ConcLusion}

This controlled experiment showed that although the scale and intensity of damage were great, abundant advance regeneration, understory vegetation, and damaged trees remained, allowing the forest to resist changes in ecosystem processes and invasion by new species. Hurricanes generate extensive, severe damage, but even the largest disturbances do not homogenize the landscape (Foster and Boose 1992, Turner 2010), so survivors can play a key role in post-disturbance succession. What is most surprising about this study is that even with $80 \%$ canopy removal across an $8000-\mathrm{m}^{2}$ gap, early successional trees and understory plants did not strongly contribute to the post-disturbance forest development. Temperate forests are remarkably resilient to natural disturbance. Consequently, it often takes multiple or interacting disturbances, such as hurricane damage followed by salvage logging, to drive these ecosystems to an early successional phase.

\section{ACKNOWLEDGMENTS}

We thank Ann Lezberg and Sarah Cooper-Ellis for their project management from 1989 to 1998. Elaine Doughty and many undergraduate students contributed their time and thoughts to data collection and interpretation. Aaron Ellison provided guidance on data analyses. Helpful comments were provided by A. Ellison, B. Hall, S. Long, D. Orwig, C. Peterson, K. Stinson, and two anonymous reviewers. This work is a contribution to the Harvard Forest Long-Term Ecological Research Program (NSF-DEB-0620443).

\section{Literature Cited}

Aber, J. D., and A. H. Magill. 2004. Chronic nitrogen additions at the Harvard Forest: the first fifteen years of a nitrogen saturation experiment. Forest Ecology and Management 196:1-5.

Abrams, M. D. 1998. The red maple paradox. BioScience 48:355-364.

Boose, E. R., E. F. Boose, and A. L. Lezberg. 1998. A practical method for mapping trees using distance measurements. Ecology 79:819-827.

Boose, E. R., K. E. Chamberlin, and D. R. Foster. 2001. Landscape and regional impacts of hurricanes in New England. Ecological Monographs 7:27-48.

Bowden, R. D., M. C. Castro, J. M. Melillo, P. A. Steudler, and J. D. Aber. 1993. Fluxes of greenhouse gases between soils and the atmosphere in a temperate forest following a simulated hurricane blowdown. Biogeochemistry 21:61-71.

Brown, J. K. 1974. Handbook for inventorying downed woody material. USDA Forest Service General Technical Report INT-16.

Carlton, C. G., and F. A. Bazzaz. 1998. Regeneration of three sympatric birch species on experimental hurricane blowdown microsites. Ecological Monographs 68:99-120.

Cooper-Ellis, S., D. R. Foster, G. Carlton, and A. L. Lezberg. 1999. Forest response to catastrophic wind: results from an experimental hurricane. Ecology 80:2683-2696.

Crabtree, R. C., and F. A. Bazzaz. 1993. Seedling response of four birch species to simulated nitrogen deposition: ammonium vs. nitrate. Ecological Applications 3:315-321.

D'Amato, A. W., D. A. Orwig, and D. R. Foster. 2008. The influence of successional processes and disturbance on the structure of Tsuga canadensis forests. Ecological Applications 18:1182-1199.

Dietze, M. C., and J. S. Clark. 2008. Changing the gap dynamics paradigm: vegetative regeneration control on forest response to disturbance. Ecological Monographs 78:331-347.

Fajvan, M., A. Barker Plotkin, and D. R. Foster. 2006. Modeling tree regeneration height growth after an experimental hurricane. Canadian Journal of Forest Research 36:2003-2014.

Foster, D. R. 1988a. Disturbance history, community organization and vegetation dynamics of the old-growth Pisgah Forest, south-western New Hampshire, U.S.A. Journal of Ecology 76:105-134.

Foster, D. R. 1988b. Species and stand response to catastrophic wind in central New England, U.S.A. Journal of Ecology 76:135-151.

Foster, D. R., J. D. Aber, J. M. Melillo, R. D. Bowden, and F. A. Bazzaz. 1997. Forest response to disturbance and anthropogenic stress: rethinking the 1938 Hurricane and the impact of physical disturbance vs. chemical and climate stress on forest ecosystems. BioScience 47:437-445.

Foster, D. R., and E. R. Boose. 1992. Patterns of forest damage resulting from catastrophic wind in central New England. Journal of Ecology 80:79-98.

Foster, D. R., and D. A. Orwig. 2006. Pre-emptive and salvage harvesting of New England forests: when doing nothing is a viable alternative. Conservation Biology 20:959-970.

Henry, J. D., and J. M. A. Swan. 1974. Reconstructing forest history from live and dead plant material - an approach to the study of forest succession in southwest New Hampshire. Ecology 55:772-783.

Lugo, A. E. 2008. Visible and invisible effects of hurricanes: an international review. Austral Ecology 33:368-398. 
Mabry, C., and T. Korsgren. 1998. A permanent plot study of vegetation and vegetation-site factors fifty-three years following disturbance in central New England, U.S.A. Ecoscience 5:232-240.

Marshall, J. D., and R. H. Waring. 1986. Comparison of methods of estimating leaf-area index in old-growth Douglasfir. Ecology 67:975-979.

Merrens, E. J., and D. R. Peart. 1992. Effects of hurricane damage on individual tree growth and stand structure in a hardwood forest in New Hampshire, USA. Journal of Ecology 80:787-795.

Motzkin, G., P. Wilson, D. R. Foster, and A. Allen. 1999. Vegetation patterns in heterogeneous landscapes: the importance of history and environment. Journal of Vegetation Science 10:903-920.

NETSA (Northeastern Timber Salvage Administration). 1943. Report of the U.S. Forest Service Programs resulting from the New England hurricane of September 21, 1938. NETSA, Boston, Massachusetts, USA.

Oksanen, J., F. G. Blanchet, R. Kindt, P. Legendre, P. R. Minchin, R. B. O'Hara, G. L. Simpson, P. Solymos, M. H. H. Stevenes, and H. Wagner. 2012. Package 'vegan': community ecology package. R package version 2.0-4. http:// vegan.r-forge.r-project.org/

Oliver, C. D., and B. C. Larson. 1996. Forest stand dynamics. Update edition. John Wiley and Sons, New York, New York, USA.

Orwig, D. A., R. C. Cobb, A. W. D'Amato, M. L. Kizlinski, and D. R. Foster. 2008. Multi-year ecosystem response to hemlock woolly adelgid infestation in southern New England forests. Canadian Journal of Forest Research 38:834-843.

Orwig, D. A., and D. R. Foster. 1998. Forest response to the introduced hemlock woolly adelgid in southern New England, USA. Journal of the Torrey Botanical Society 125:59-72.

Papaik, M. J., and C. D. Canham. 2006. Species resistance and community response to wind disturbance regimes in northern temperate forests. Journal of Ecology 94:1011-1026.
Peterson, C. J., and S. T. A. Pickett. 2000. Patch type influences on regeneration in a western Pennsylvania, USA, catastrophic windthrow. Oikos 90:489-500.

Putz, F. E., and N. V. L. Brokaw. 1989. Sprouting of broken trees on Barro Colorado Island, Panama. Ecology 70:508512 .

R Development Core Team. 2009. R 2.9.2. R Foundation for Statistical Computing, Vienna, Austria.

Roberts, M. R. 2004. Response of the herbaceous layer to natural disturbance in North American forests. Canadian Journal of Botany 82:1273-1283.

Rowlands, W. 1941. Damage to even-aged stands in Petersham, Massachusetts, by the 1938 Hurricane as influenced by stand condition. Thesis. Harvard University, Cambridge, Massachusetts, USA.

Sipe, T. W., and F. A. Bazzaz. 1994. Gap partitioning among maples (Acer) in central New England: survival and growth. Ecology 76:1587-1602.

Spurr, S. H. 1956. Natural restocking of forests following the 1938 hurricane in central New England. Ecology 37:443-451.

Turner, M. G. 2010. Disturbance and landscape dynamics in a changing world. Ecology 91:2833-2849.

Veblen, T. T. 1992. Regeneration dynamics. Pages 152-187 in D. C. Glenn-Lewin, R. K. Peet, and T. T. Veblen, editors. Plant succession: theory and prediction. Chapman and Hall, London, UK.

Ward, J. S., and G. R. Stephens. 1996. Influence of crown class on survival and development of Betula lenta in Connecticut, U.S.A. Canadian Journal of Forest Research 26:277-288.

Whitmore, T. C. 1989. Canopy gaps and the two major groups of forest trees. Ecology 70:536-538.

Zeileis, A., F. Leish, K. Hornik, and C. Kleiber. 2002. strucchange: an $\mathrm{R}$ package for testing for structural change in linear regression models. Journal of Statistical Software $7: 1-38$.

Zeng, H., J. Q. Chambers, R. I. Negron-Juarez, G. C. Hurtt, D. B. Baker, and M. D. Powell. 2009. Impacts of tropical cyclones on U.S. forest tree mortality and carbon flux from 1851-2000. Proceedings of the National Academy of Sciences USA 106:7888-7892.

\section{Supplemental Material}

Appendix A

Basal area and density over time in the pulldown and control plots (Ecological Archives E094-035-A1).

\section{Appendix B}

Understory vegetation composition table (Ecological Archives E094-035-A2).

\section{Appendix C}

Additional statistical output for ANCOVA and breakpoint analyses (Ecological Archives E094-035-A3). 